\title{
Diabetes and multidrug-resistance gene mutation: tuberculosis in Zunyi, Southwest China
}

\author{
Mu Lin, Jiangrong Liao, Yadong Gong, Xiaojing Han, Yunhua Chen, Zhu Tang, Qingqing Ma \\ Central Laboratory of Guizhou Aerospace Hospital, Zunyi, China \\ Contributions: (I) Conception and design: M Lin, Q Ma; (II) Administrative support: J Liao; (III) Provision of study materials or patients: Y Chen, \\ Z Tang; (IV) Collection and assembly of data: M Lin, X Han; (V) Data analysis and interpretation: M Lin, Y Gong; (VI) Manuscript writing: All \\ authors; (VII) Final approval of manuscript: All authors. \\ Correspondence to: Qingqing Ma. Central Laboratory of Guizhou Aerospace Hospital, Zunyi, China. Email: 1053596072@qq.com.
}

\begin{abstract}
Background: The aim of this study was to clarify the characteristics of gene mutation related to multidrug-resistance (MDR) of tuberculosis (TB) and diabetes in Zunyi.

Methods: A total 763 patients with TB were screened for TB-DNA, TB-RNA, and acid-fast staining (all were positive). They were divided into the tuberculosis (TB) group and the diabetes mellitus-tuberculosis (DM-TB) group. We compared and analyzed the MDR gene $r p o B, K a t G$, and $i n h A$ characteristics of gene mutations in the two groups by polymerase chain reaction (PCR)-reverse dot hybridization, and collected relevant clinical data to explore its correlation with the occurrence of multidrug resistance.

Results: Multidrug resistance occurred in 32 of the 525 patients in the TB group, and extensive drug resistance occurred in 15 of the 207 patients in the DM-TB group. In the DM-TB group, the mutation rates of ropBS531L and ropB531 (both 53.33\%) were lower than those of the TB group (both 59.38\%) in rifampicin resistance mutations. Most of the mutations were at the KatG315N site, conferring isoniazid resistance.

Conclusions: The mutation sites of multidrug-resistant patients in Zunyi are mainly ropB531 and ropBS531L mutations, which are prone to co-occurrence; patients with MDR-TB alone are prone to mutations at the KatG315N site, while patients with diabetes and MDR-TB are more likely to have inhA$15 \mathrm{M}$ site mutations.
\end{abstract}

Keywords: Tuberculosis (TB); diabetes; multi-drug-resistance (MDR); gene mutation

Submitted May 07, 2020. Accepted for publication Aug 26, 2020.

doi: 10.21037/apm-20-1368

View this article at: http://dx.doi.org/10.21037/apm-20-1368

\section{Introduction}

Tuberculosis (TB) and diabetes mellitus (DM) are both chronic diseases, and when they co-occur, they can be aggravated by mutual influence (1). DM has been shown to negatively impact TB treatment outcomes that the risk of TB disease is increased over 3-fold in people with diabetes compared to people without DM (2). TB can aggravate the disorder of glucose metabolism and make the blood sugar level of DM patients difficult to control. DM can lead to protein and fat metabolism disorders, which can reduce immune function and aggravate the condition of TB patients $(3,4)$. DM has been shown to have a negative impact on immune function through the accumulation of advanced glycation end-products that alter phagocyte function (5). TB patients with $\mathrm{DM}$ is treated with multidrug therapy [rifampin (RIF) and isoniazid (INH)] for the 6 months of treatment compare with TB patients, TB treatment outcomes are worse in patients with DM (6). The risk of death or treatment failure was 1.7 times higher in TB patients with DM than in those without DM (7). However, an important problem in TB treatment is anti-mycobacterial resistance. DM patients with $\mathrm{TB}$ are also more likely 
Table 1 Diagnostic criteria for studying related diseases

\begin{tabular}{lll}
\hline Disease & Diagnostic principle & Basis for diagnosis \\
\hline Tuberculosis & Clinical manifestation & $\begin{array}{l}\text { Cough } \geq 2 \text { weeks, blood or hemoptysis in the sputum, night sweats, fatigue, intermittent } \\
\text { or persistent low fever, loss of appetite, weight loss, and other symptoms }\end{array}$ \\
& Bacteriological examination & The smear microscopy positive (positive acid-resistant dyeing) \\
& Molecular biology test & Nucleic acid testing positive for Mycobacterium tuberculosis \\
Type 2 diabetes & Clinical manifestation & Typical symptoms of diabetes (polyuria, polydipsia, and unexplained weight loss) \\
& Laboratory inspection & Arbitrary blood glucose $\geq 11.1 \mathrm{mmol} / \mathrm{L}$, fasting blood glucose (FPG) $\geq 7.0 \mathrm{mmol} / \mathrm{L}$
\end{tabular}

Sources of diagnostic criteria: diagnostic criteria for tuberculosis (WS 288-2017) and guidelines for the diagnosis and treatment of diabetes (ADA 2013).

to develop multidrug-resistant TB (MDR-TB) (8). $16 \%$ diabetic TB patients showed multi drug resistance (MDR) which was three times higher than resistance (5.9\%) found in non-diabetic TB patients (9). RIF and INH is the two most effective anti-TB drugs, resistance to RIF and INH is multidrug-resistant (MDR) TB. Rifampin resistance is conferred by chromosomal mutations in the rpoB gene encoding the $\beta$ subunit of the RNA polymerase (RpoB). Most rifampin-resistance-conferring mutations in Mtb clinical isolates are due to amino acid changes at codons 531, 526, 522, and 513 of RpoB (10). The mutation of katG or inhA is the major mechanism of INH resistance. KatG S315 mutation is the most common mutation in INH-resistant strains and accounts for more than half of the resistant clinical isolates (11). Furthermore, accompanying multidrug resistance will greatly increase the difficulty of treating the disease.

There were 10 million new cases of $\mathrm{TB}$ worldwide in 2018, with China accounting for $9 \%$ of cases and ranking second in the world in incidence (12). Guizhou province is a high incidence area and has the fourth highest incidence rate of $\mathrm{TB}$ in China, with the highest drug-resistance rate. Cases are mainly concentrated around Zunyi, Bijie, Tongren, and southeast Guizhou (13). In particular, the emergence of multidrug-resistant tuberculosis (MDR-TB) has brought more serious challenges to the prevention and control of TB worldwide (14). MDR-TB is a condition in which Mycobacterium tuberculosis is at least resistant to rifampin (RIF) and isoniazid (INH) (15). RIF and INH, as key first-line drugs in anti-TB treatment programs, have always played an important role in the treatment of TB. However, the emergence of MDR-TB may be related to the mutations of the $r p o B, k a t G$, and $i n h A$ genes of the two drug-related targets $(16,17)$. This study selected TB patients in Zunyi and used polymerase chain reaction
(PCR) to detect mycobacterial DNA and RNA (18) for the purpose of investigating the correlation between TB and diabetes mellitus with tuberculosis (DM-TB) in Zunyi. It is hoped the findings can clarify the relationship between the resistance-causing MTB-TB mutations of $r p o B$, katG, and inh $A$ and the molecular biological characteristics of MDRTB. We present the following article in accordance with the MDAR reporting checklist (available at http://dx.doi. org/10.21037/apm-20-1368).

\section{Methods}

\section{General information}

This study collected sputum or irrigating fluid specimens from 763 pulmonary TB patients (according to the WS 288-2017 diagnostic criteria for pulmonary TB, Table 1) treated in the Department of Respiratory and Intensive Medicine of our hospital from December 2017 to July 2019. We detected the DNA, RNA, and acid-fast staining of Mycobacterium tuberculosis and yielded positive results for rifampicin and isoniazid resistance gene testing (primer sequences for rifampin and isoniazid resistance detection, Table 2). We then compared the correlation between multidrug resistance in TB patients and TB-DM patients (according to the American Diabetes Association 2013 standardization diagnosis and treatment guidelines for diabetes, Table 1). Meanwhile, we collected the relevant clinical data of the included patients. The research process is shown in Figure 1.

The study was conducted in accordance with the Declaration of Helsinki (as revised in 2013), and was approved by the Guizhou Aerospace Hospital Medical Ethics Management Committee, and written informed consent was obtained from all patients. 
Table 2 Primer sequences for detection of resistance to rifampicin and isoniazid

\begin{tabular}{llcc}
\hline Gene & Primer & Sequence & Size of product (bp) \\
\hline rpoB & rpoB-F & 5'-TACGGTCGGCGAGCTGATCG-3' & 411 \\
& rpoB-R & 5'-TACGGCGTTTCGATGAACC-3' & 423 \\
inhA & katG-F & 5'-TCGTATGGCACCGGAACC-3' & 123 \\
& inhA-F & 5 '-CAGCTCCCACTCGTAGCC-3' & 126 \\
\hline
\end{tabular}

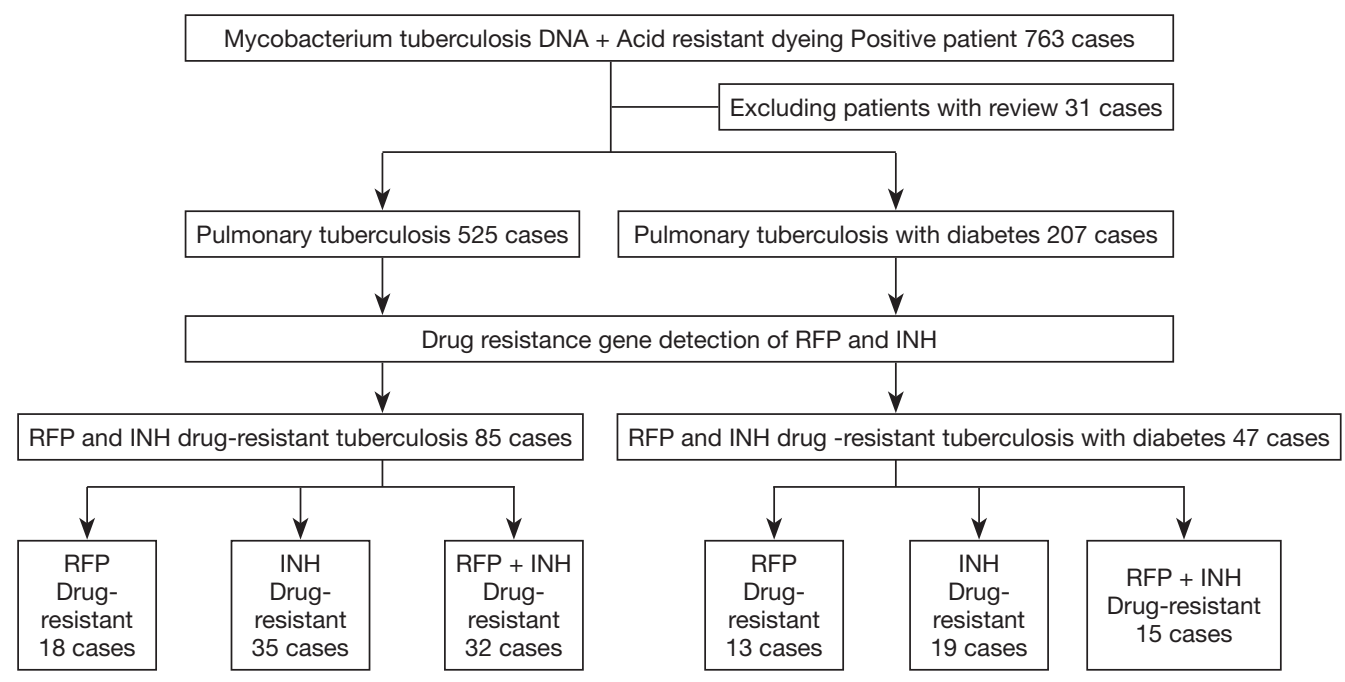

Figure 1 Research plan flow chart.

\section{Main instruments and reagents}

The main equipment used was Hongshi SLAN-96P fluorescence quantitative PCR instrument (Shanghai, China), ABI-2710 Nucleic acid Amplifier (Applied Biosystems, USA), Yaneng YN-H16 Constant Temperature Hybridization Instrument (Shenzhen, China), Rendu FZP1 Nucleic Acid Purification Instrument (Shanghai, China), Aosheng Micro Spectrophotometer Nano-100 (Hangzhou, China). A Mycobacterium nucleic acid detection kit (PCRfluorescent Probe Method; article number 301031) was obtained from Chengdu Boao Jingxin Biotechnology Co, Ltd (Chengdu, China). A Mycobacterium TB nucleic acid detection kit (RNA constant temperature amplification; article number 20153401875) was acquired from Shanghai Rendu Biological Technology Co, Ltd (Shanghai, China). The Mycobacterium TB rifampicin resistance gene detection kit (PCR-reverse Dot Hybridization Method; article number 20153400356) was provided by Asia Energy Biotechnology Co, Ltd (Shenzhen, China).

\section{MTB DNA and RNA testing}

\section{MTB DNA and RNA extraction}

An equal volume of sodium hydroxide was added (concentration of $4 \%$ ) to the patient's sputum or bronchial lavage fluid sample, shaken, mixed, and then left to stand for 15 minutes to fully liquefy. This mixture was centrifuged at $12,000 \mathrm{rpm} / \mathrm{min}$ for 10 minutes, and the supernatant was discarded afterwards. Next, $1 \mathrm{~mL}$ of cleaning solution (with the main component being normal saline) was added and mixed well; the mixture was centrifuged at $12,000 \mathrm{rpm} / \mathrm{min}$ for 5 minutes, and the supernatant was discarded afterwards. The pellet was divided into two tubes with $50 \mu \mathrm{L}$ of nucleic acid extract (for DNA extraction) and $50 \mu \mathrm{L}$ of dilution being added (for RNA extraction), with ultrasonic 
Table 3 rpoB, $k a t G$, and $i n b A$ gene mutation sites

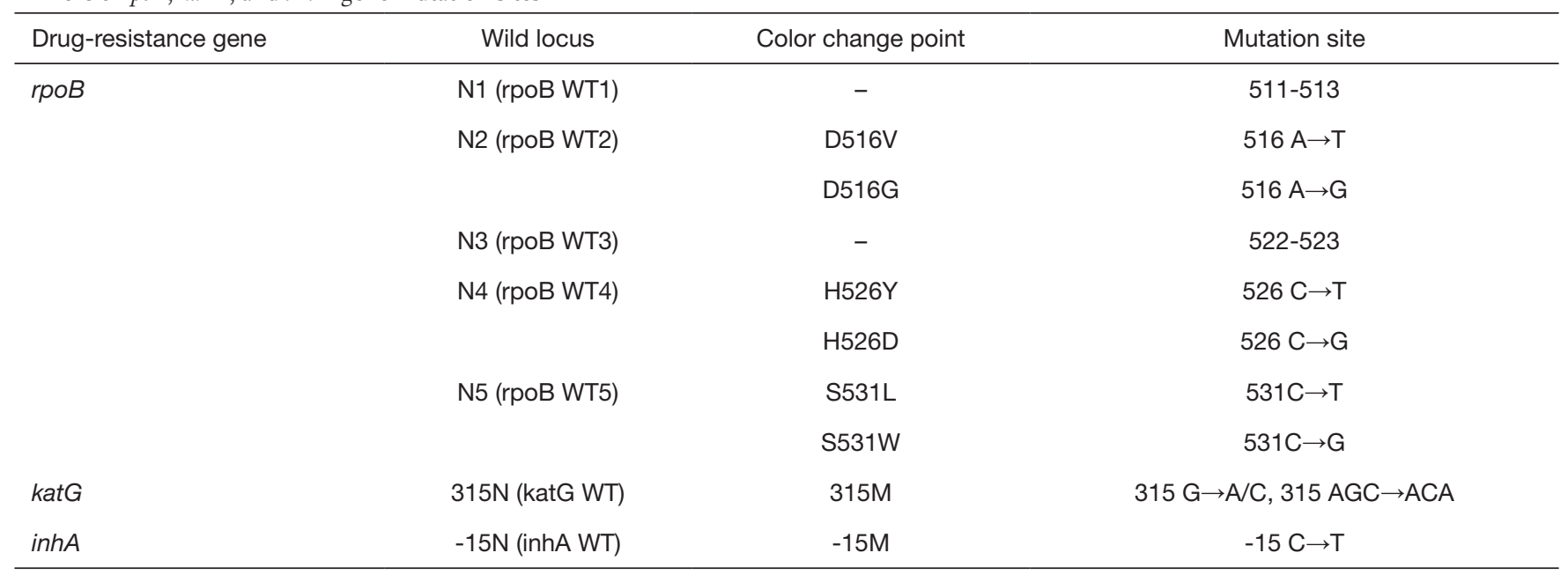

crack applied for 10 minutes. The DNA extraction tube was placed in a shaking metal bath. The tube was shaken at $1,800 \mathrm{rpm} / \mathrm{min}$ at $100^{\circ} \mathrm{C}$ for $10 \mathrm{~min}$, centrifuged at $12,000 \mathrm{rpm} / \mathrm{min}$ for 5 minutes, and the supernatant was collected. The RNA extraction tube was directly centrifuged at $12,000 \mathrm{rpm} / \mathrm{min}$ for $5 \mathrm{~min}$, and the supernatant was collected.

\section{MTB DNA and RNA testing}

To begin, $20 \mu \mathrm{L}$ of MTB DNA PCR reaction system was formed using $18 \mu \mathrm{L}$ of probes, Taq enzymes, and primers, along with $2 \mu \mathrm{L}$ of templates. The amplification procedure included 1 cycle at $37^{\circ} \mathrm{C}$ for $300 \mathrm{~s}$ and at $94{ }^{\circ} \mathrm{C}$ for $180 \mathrm{~s} ; 40$ cycles at $94{ }^{\circ} \mathrm{C}$ for $15 \mathrm{~s}$ and at $60{ }^{\circ} \mathrm{C}$ for $30 \mathrm{~s}$; and 1 cycle at $50{ }^{\circ} \mathrm{C}$ for $10 \mathrm{~s}$. Then, $32 \mu \mathrm{L}$ of MTB RNA PCR reaction system was formed using $30 \mu \mathrm{L}$ of probes, reverse transcriptases, and primers, along with $2 \mu \mathrm{L}$ of templates. The amplification program was 40 cycles of constant temperature amplification at $42{ }^{\circ} \mathrm{C}$ for $60 \mathrm{~s}$. The results were interpreted as positive, and the DNA amplification products were kept in the refrigerator at $-20^{\circ} \mathrm{C}$.

\section{Acid-fast staining}

The experiment was completed by our laboratory. Briefly, 2-3 drops of carbohydrate acid red were used after initial dyeing, and the slide was rinsed with water, decolorized with $3 \%$ hydrochloric acid alcohol for 30 seconds to 1 minute, rinsed with water again, washed with alkaline Meilan solution for 1 minute, and washed with water. After the slide had absorbed the water, 1-2 drops of cedar oil on the glass slide, carefully observe and count under a high magnification lens (also called oil lens). The number of MTB DNA- and RNA-positive subjects was counted, and the positive acid-fast staining results were compared. Then, the relevant clinical information of the above patients was collected.

\section{Blood glucose measurement}

The blood glucose and fasting blood glucose of the included patients were tested. According to the diagnostic criteria in Table 1, the patients were divided into a simple tuberculosis group and a tuberculosis combined with diabetes group.

\section{PCR-reverse dot hybridization}

\section{PCR amplification}

First, $25 \mu \mathrm{L}$ of reaction system were formed using $21 \mu \mathrm{L}$ of dNTP, Taq enzyme, and primers, along with $4 \mu \mathrm{L}$ of template DNA. The amplification program was at $50{ }^{\circ} \mathrm{C}$ for $120 \mathrm{~s}$ and at $94{ }^{\circ} \mathrm{C}$ for $600 \mathrm{~s}$; at $95^{\circ} \mathrm{C}$ for $45 \mathrm{~s}$ through 1 cycle, at $68{ }^{\circ} \mathrm{C}$ for $60 \mathrm{~s}$ through 30 cycles; at $95{ }^{\circ} \mathrm{C}$ for $30 \mathrm{~s}$, at $54^{\circ} \mathrm{C}$ for $30 \mathrm{~s}$, and at $68^{\circ} \mathrm{C}$ for $60 \mathrm{~s}$ through 30 cycles; and at $68{ }^{\circ} \mathrm{C}$ for $600 \mathrm{~s}$ through 1 cycle. Table 3 summarizes the mutation sites of rifampin- and isoniazid- resistance testing.

\section{Hybridization and color development}

The strips were numbered and placed in a $15 \mathrm{~mL}$ centrifuge tube containing PCR amplification product buffer. After $10 \mathrm{~min}$ at $100^{\circ} \mathrm{C}$ and $90 \mathrm{~min}$ at $59^{\circ} \mathrm{C}$, the membranes 
Table 4 General conditions of patients with multidrug-resistant tuberculosis

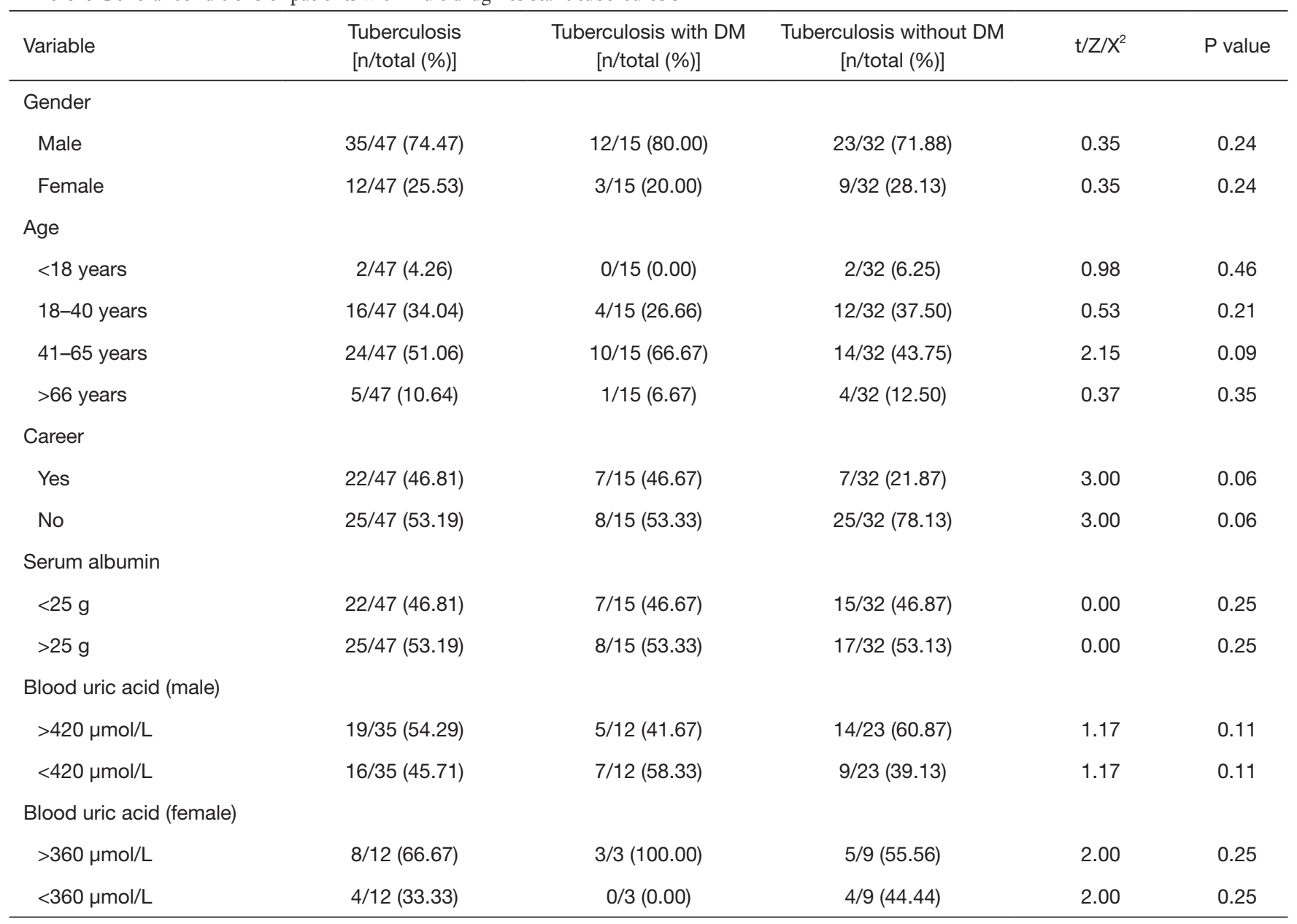

DM, diabetes mellitus.

strip was placed into a $50 \mathrm{~mL}$ centrifuge tube containing sodium citrate buffer, and washed gently at $59^{\circ} \mathrm{C}$ for $15 \mathrm{~min}$. The membranes were stripped into the coloring solution containing horseradish peroxidase for $10 \mathrm{~min}$, the corresponding coloring point was observed, and the mutations of rpoB, katGm and $i n h A$ genes were interpreted.

\section{Statistical analysis}

SPSS 22. 0 statistical software package was used for analysis. The measurement data conforming to the normal distribution are expressed as $\bar{x} \pm s$, and the comparison between the two groups was performed by independent samples $t$-test; the measurement data of the non-normal distribution were measured by median and quartiles. $[M$ (P25, P75)] indicates that the comparison between groups should be performed by the Mann-Whitney $U$ test; the count data are expressed by frequency or percentage, and the comparison between groups was performed by $\chi^{2}$ test. A $\mathrm{P}$ value $<0.05$ indicated that the difference was statistically significant.

\section{Results}

Analysis of related factors

In the comparisons of gender, age, occupation, and other factors, along with the serum albumin test results of $\mathrm{TB}$ patients and TB-DM patients, the differences between the groups were found to not be statistically significant (Table 4). However, in the TB and diabetes group, gender $\left(\chi^{2}=10.80\right.$, $\mathrm{P}<0.01)$, age $\left(\chi^{2}=21.60, \mathrm{P}<0.01\right)$ and female blood uric acid level $\left(\chi^{2}=6.00, \mathrm{P}<0.05\right)$, and other related factors showed 


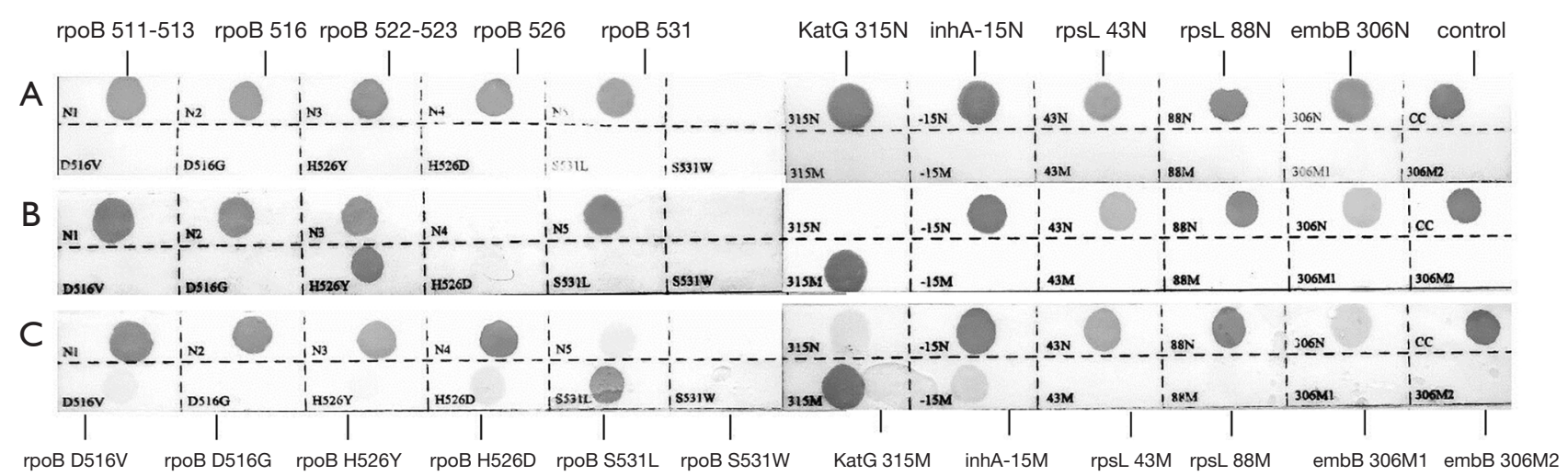

Figure 2 High-throughput reverse dot hybridization of $r p o B, k a t G$ and $i n h A$ gene detection results. (A) $r p o B, k a t G$, and $i n h A$ gene wild-type rifampicin-sensitive; (B) rpoB gene 522-523 locus wild and H526Y, H526D locus mutation mixed rifampicin resistance, and kat $G$ gene $315 \mathrm{M}$ site mutation isoniazid resistance; (C) rpoB gene 511-513, 526, and 531 locus wild and D516V, H526D, and S531L site mutation mixed rifampicin resistance; $k a t G$ gene $315 \mathrm{~N}$ and $-15 \mathrm{~N}$ wild, and $315 \mathrm{M}$ and $-15 \mathrm{M}$ mutant mixed isoniazid resistance.

statistical differences. In the simple TB group, gender $\left(\chi^{2}=12.25, \mathrm{P}<0.01\right)$, age $\left(\chi^{2}=17.33, \mathrm{P}<0.01\right)$, occupation $\left(\chi^{2}=20.25, \mathrm{P}<0.01\right)$ and other related factors showed statistical differences.

\section{PCR-reverse dot hybridization test results}

rpoB, kat $G$, and $i n b A$ genes were detected in 732 patients with pulmonary $\mathrm{TB}$, including 32 cases of multidrug resistance and 15 cases of multidrug resistance combined with diabetes (Figure 2).

\section{Mutation rate of drug resistance sites in patients with $M D R-T B$}

In the comparison of 32 patients with MDR and 15 patients with MDR combined with diabetes concerning the mutation rate of rpoB, $k a t G$, and $i n h A$ gene sites, patients with simple MDR-TB were found to be prone to KatG315N site mutation, while InhA-15M mutations were more likely to occur in patients with diabetes combined with MDR-TB. However, the differences between the remaining groups were not statistically significant (Table 5).

\section{Distribution of resistance gene rpoB mutation sites}

When rifampicin resistance occurred in patients with MDR-TB, mutations at ropB531 and ropBS531L sites were most likely to concomitantly occur. For isoniazid resistance, the mutation rate at the $K a t G$ gene was higher, and MDR-
TB patients were prone to the KatG315N site mutation. Diabetes patients with MDR-TB were more prone to inhA$15 \mathrm{M}$ site mutation, but there were no obvious differences in other mutation sites (Figure 3).

\section{Discussion}

With the changes in people's lifestyles and dietary structures, the incidence of TB with diabetes has increased year by year. This particular combination of disease increases the body's catabolism, causes a decrease in appetite, and affects the secretory function of the pancreas. Furthermore, the abnormal glucose metabolism of the condition is also likely to cause protein and fat metabolism disorders, leading to malnutrition and decreased cellular immune function, which further exacerbate the disease $(19,20)$. If multidrug resistance reoccurs, it can seriously affect the treatment of patients, which not only increases the difficulty and cost of treatment, but also makes it difficult to control the disease, resulting in a reduction in cure rate and a rise in mortality (21). Therefore, early diagnosis of drugresistant TB is the key to improving treatment efficacy. As an alternative to the culture method, molecular biology methods have been used to detect resistance mutations in rifampin and isoniazid, offering timely, accurate, and reliable detection results.

In this study, $763 \mathrm{~TB}$ patients' sputum or sputum samples were tested for DNA, RNA, and acid-fast staining. The results were positive for rifampicin- and isoniazid-resistance genes. In a total of 525 patients with TB, there were 32 
Table 5 Drug resistance sites in patients with multidrug-resistant tuberculosis

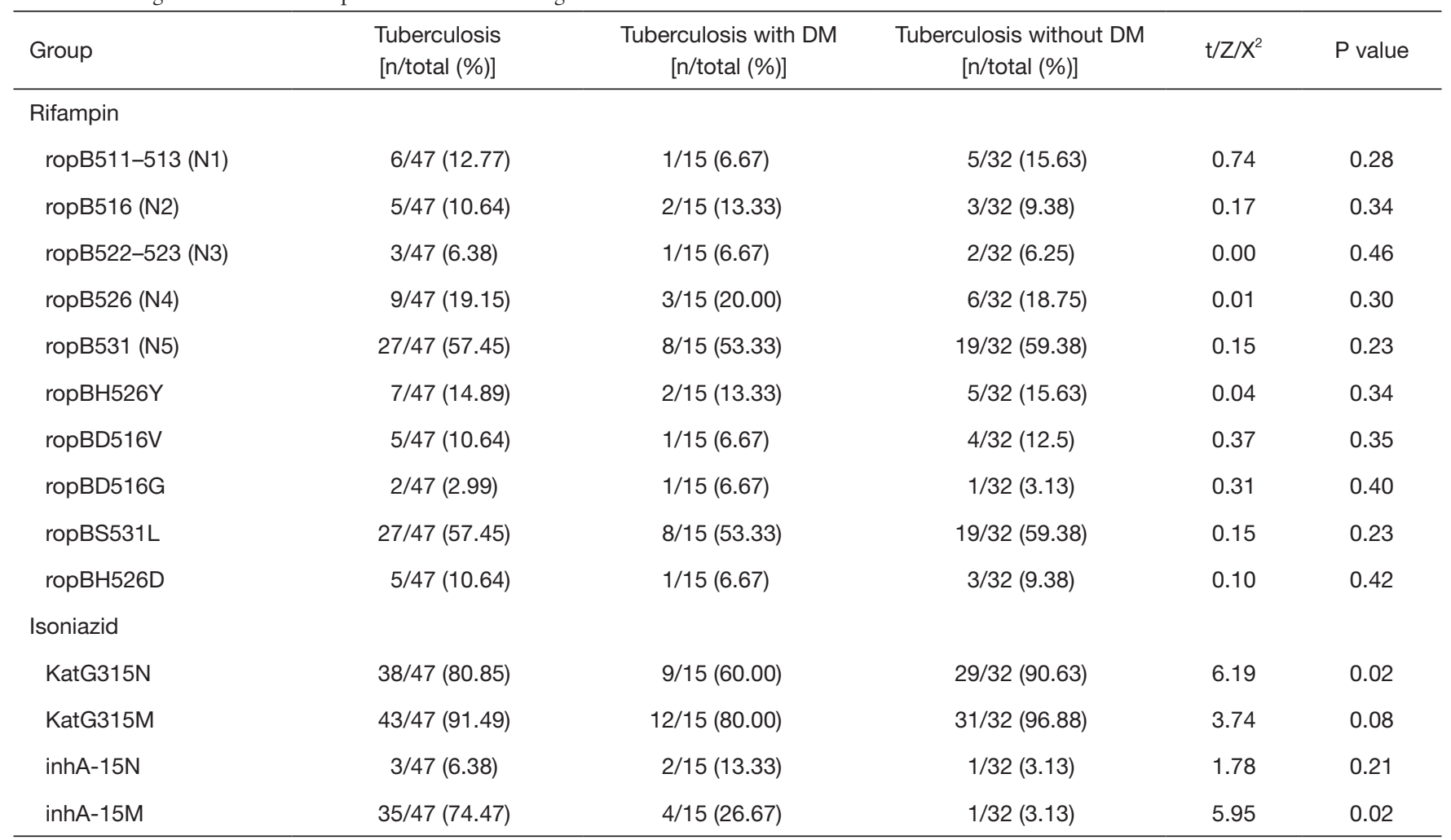

DM, diabetes mellitus.
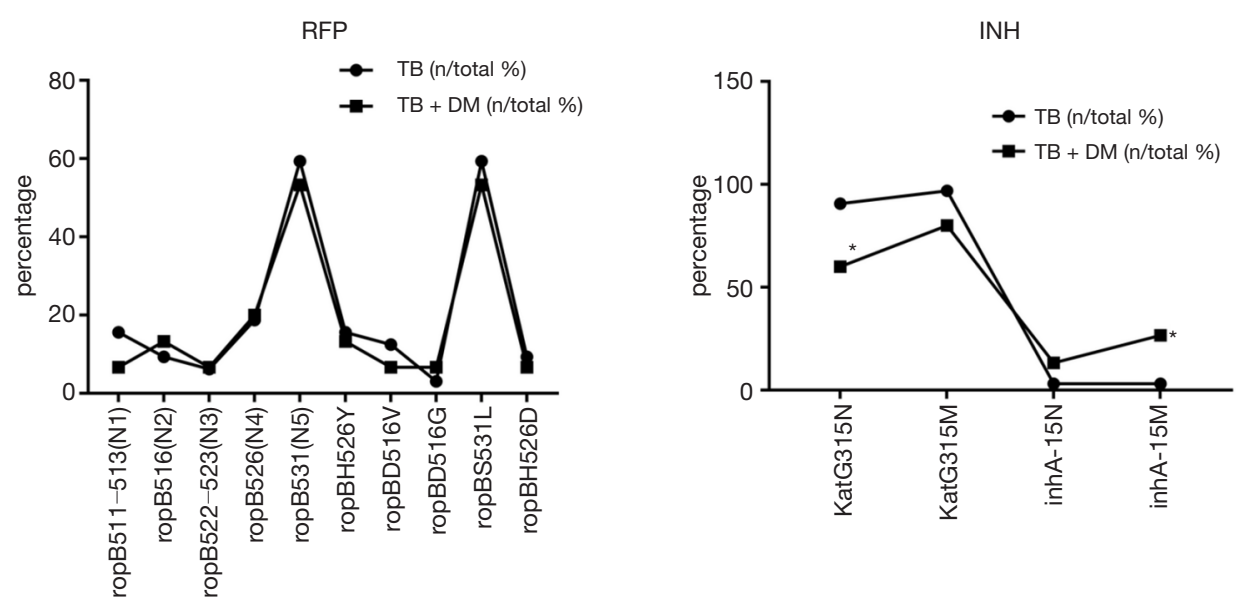

Figure 3 Comparison of site mutations of the $r p o B, k a t G$, and $i n h A$ drug-resistance genes in multidrug-resistant tuberculosis patients and multidrug-resistant diabetes mellitus patients. *, indicates statistical difference.

multi-drug resistant patients, while in a total of 207 patients with TB-DM patients, there were 15 multi-drug resistant patients. The mutation sites of $\operatorname{rop} B$ gene were more common with ropBS531L and ropB531 mutations, and the two sites were mostly accompanied by mutations, which is consistent with both Chinese and international studies (22). The mutation rate of ropB531 in the TB group (57.69\%) was higher than that in Fujian (53.3\%) and Sichuan province 
(55.87\%), but lower than that in Guangdong (63.22\%) and Guangxi (59.26\%) (23). The mutation sites of the kat $G$ gene were more common with katG $315 \mathrm{~N}$ and katG $315 \mathrm{M}$, and the two sites were commonly associated with mutations, which is consistent with Chinese and international studies (24). The mutation rate of katG 315 in the TB group $(315 \mathrm{~N}$ was $82.35 \%, 315 \mathrm{M}$ was $86.76 \%$ ) was higher than that in Fujian (54.35\%) and lower than that in Wuhan (88.71\%) (25). The mutation rate of inhA-15 locus in the TB group (16.18\%) was slightly lower than that in Jiangxi (15.9\%), which confirms that there are obvious regional differences in the frequency of the $\mathrm{katG}$ and $i n h A$ gene mutations (26). The frequency of gene mutations varies across different countries and regions (27), which may be related to the evolution of local Mycobacterium in $T B$. In this experiment, for the first time, the sites of multidrug resistance mutations in patients with diabetes and pulmonary TB in Zunyi were counted. Patients with simple MDR-TB are susceptible to KatG315N site mutations, while patients with diabetes and MDR-TB are more prone to inhA-15M site mutations.

Patients with TB and diabetes are mostly middleaged and elderly men, which may be related to the characteristics of diabetes susceptibility, while women with $\mathrm{TB}$ and diabetes have higher blood uric acid levels. TB patients were mostly men without fixed occupations, but, because the sample size was too small, we could not rule out accidental factors. This study analyzed the correlation between relevant clinical indicators and multidrug-resistant TB infection, and found that, compared with patients with TB, the serum albumin level of patients with TB and diabetes were slightly lower, which may be associated with the fact that TB and diabetes patients cannot fully utilize glucose, which is needed to break down proteins and fats to provide calories and reduce the body's albumin synthesis (28). However, due to the limited sample size, the relevant results are not statistically significant, and thus the sample size needs to be expanded in further research.

\section{Acknowledgments}

Funding: This study was funded by the Zunyi Science and Technology Bureau of Guizhou Province [Zunshi Kehe Support NS (019) No. 6; Zunshi Kehe Shezi (2018) No. 30].

\section{Footnote}

Reporting Checklist: The authors have completed the MDAR reporting checklist. Available at http://dx.doi.org/10.21037/ apm-20-1368

Data Sharing Statement: Available at http://dx.doi. org/10.21037/apm-20-1368

Conflicts of interest: All authors have completed the ICMJE uniform disclosure form (available at http://dx.doi. org/10.21037/apm-20-1368). The authors have no conflicts of interest to declare.

Ethical Statement: The authors are accountable for all aspects of the work in ensuring that questions related to the accuracy or integrity of any part of the work are appropriately investigated and resolved. The study was conducted in accordance with the Declaration of Helsinki (as revised in 2013), and was approved by the Guizhou Aerospace Hospital Medical Ethics Management Committee, and written informed consent was obtained from all patients.

Open Access Statement: This is an Open Access article distributed in accordance with the Creative Commons Attribution-NonCommercial-NoDerivs 4.0 International License (CC BY-NC-ND 4.0), which permits the noncommercial replication and distribution of the article with the strict proviso that no changes or edits are made and the original work is properly cited (including links to both the formal publication through the relevant DOI and the license). See: https://creativecommons.org/licenses/by-nc-nd/4.0/.

\section{References}

1. Céspedes C, López L, Aguirre S, et al. Prevalence of comorbidity tuberculosis and diabetes mellitus in Paraguay, 2016 and 2017. Rev Panam Salud Publica 2019;43:e105.

2. Al-Rifai RH, Pearson F, Critchley JA, et al. Association between diabetes mellitus and active tuberculosis: a systematic review and meta-analysis. PLoS One 2017;12:e0187967.

3. Ferlita S, Yegiazaryan A, Noori N, et al. Type 2 Diabetes Mellitus and Altered Immune System Leading to Susceptibility to Pathogens, Especially Mycobacterium tuberculosis. J Clin Med 2019;8:2219.

4. Awad SF, Critchley JA, Abu-Raddad LJ. Epidemiological impact of targeted interventions for people with diabetes mellitus on tuberculosis transmission in 
India: Modelling based predictions. Epidemics 2019;30:100381.

5. Kumar Nathella P, Babu S. Influence of diabetes mellitus on immunity to human tuberculosis. Immunology 2017;152:13-24.

6. Degner NR, Wang JY, Golub JE, et al. Metformin use reverses the increased mortality associated with diabetes mellitus during tuberculosis treatment. Clin Infect Dis 2018;66:198-205.

7. Viswanathan V, Vigneswari A, Selvan K, et al. Effect of diabetes on treatment outcome of smear-positive pulmonary tuberculosis-a report from South India. J Diabetes Complications 2014;28:162-5.

8. Lee PH, Fu H, Lai TC, et al. Glycemic control and the risk of tuberculosis: a cohort study. PLoS Med 2016;13:e1002072.

9. Munir MK, Adnan M, Shabbir I, et al. Therapeutic Outcome of Pulmonary Tuberculosis in Type-2 Diabetes Patients. APMC Volume 12, Number 2 April - June 2018.

10. Arriaga MB, Torres N, Araujo N, et al. Impact of the change in the antitubercular regimen from three to four drugs on cure and frequency of adverse reactions in tuberculosis patients from Brazil: A retrospective cohort study. PLoS One 2019;14:e0227101.

11. Vilcheze C, Jacobs WR Jr. Resistance to isoniazid and ethionamide in mycobacterium tuberculosis: genes, mutations, and causalities. Microbiology Spectrum 2, MGM2-0014-2013.

12. Gu Y, Wu C, Yu F, et al. Application of endobronchial ultrasonography using a guide sheath and electromagnetic navigation bronchoscopy in the diagnosis of atypical bacteriologically-negative pulmonary tuberculosis. Ann Transl Med 2019;7:567.

13. Dai X, Wang L, Li R, et al. Different diagnostic procedures for diagnosing tuberculosis. China Public Health 2019;35:894-9.

14. Wang Z. Research progress of drug-resistant tuberculosis. Infectious Disease Information 2018;31:9-23.

15. Wei H, Long Y, Ling J, et al. Characteristics of resistance gene of Mycobacterium tuberculosis rifampin and isoniazid in Baise of Guangxi. Journal of Practical Medicine 2015;31:731-23.

16. Jani J, Mustapha ZA, Jamal NB, et al. Whole genome sequencing data and analysis of a rifampicin-resistant Mycobacterium tuberculosis strain SBH162 from Sabah, Malaysia. Data Brief 2019;26:104445.
17. Mvelase NR, Pillay M, Sibanda W, et al. rpoB Mutations Causing Discordant Rifampicin Susceptibility in Mycobacterium tuberculosis: Retrospective Analysis of Prevalence, Phenotypic, Genotypic, and Treatment Outcomes. Open Forum Infect Dis 2019;6:ofz065.

18. Hameed HMA, Tan Y, Islam MM, et al. Phenotypic and genotypic characterization of levofloxacin- and moxifloxacin-resistant Mycobacterium tuberculosis clinical isolates in southern China. J Thorac Dis 2019;11:4613-25.

19. Kumar NP, Moideen K, Nancy A, et al. Systemic RAGE ligands are upregulated in tuberculosis individuals with diabetes co-morbidity and modulated by anti-tuberculosis treatment and metformin therapy. BMC Infect Dis 2019;19:1039.

20. Torres M, Herrera MT, Fabián-San-Miguel G, et al. The Intracellular Growth of M. tuberculosis Is More Associated with High Glucose Levels Than with Impaired Responses of Monocytes from T2D Patients. J Immunol Res 2019;2019:1462098.

21. Ruesen C, Chaidir L, Ugarte-Gil C, et al. Diabetes is associated with genotypically drug-resistant tuberculosis. Eur Respir J 2020;5 5:1901891.

22. Wang JJ, Zhou ML, Chen C, et al. Survival time and influencing factors in multidrug-resistant tuberculosis patients in Wuhan, 2006-2014). Zhonghua Liu Xing Bing Xue Za Zhi 2019;40:1409-13.

23. Dai X. Study on the Treatment Results and Influencing Factors of Rifampicin-resistant Pulmonary Tuberculosis Patients under the Comprehensive Mode of "Medical Cooperation". 2017;01.

24. Zhu Y. Evaluation of the therapeutic effect of treatment with isoniazid and rifampin on patients with isoniazidresistant or rifampin-resistant pulmonary tuberculosis. Clin Exp Reprod Med 2016;15:1297-9.

25. Guo Z, Chen X, Li X, et al. Clinical significance of direct detection of rpoB, katG and inhA resistance genes in pulmonary tuberculosis sputum smear positive specimens. Chinese and Foreign Medical 2019;38:32-5.

26. Wang X, Liu J, Shen J, et al. Drug resistance of isoniazid and prothioniconamide in patients with pulmonary tuberculosis in Chongqing. Chinese Journal of Zoonoses 2019;35:173-8.

27. Al-Mutairi NM, Ahmad S, Mokaddas EM. Molecular characterization of multidrug-resistant Mycobacterium tuberculosis (MDR-TB) isolates identifies local 
transmission of infection in Kuwait, a country with a low incidence of TB and MDR-TB. Eur J Med Res 2019;24:38.

28. Vrieling F, Alisjahbana B, Sahiratmadja E, et al. Plasma metabolomics in tuberculosis patients with and without concurrent type 2 diabetes at diagnosis and during antibiotic treatment. Sci Rep 2019;9:18669.

(English Language Editor: J. Gray)

Cite this article as: Lin M, Liao J, Gong Y, Han X, Chen Y, Tang Z, Ma Q. Diabetes and multidrug-resistance gene mutation: tuberculosis in Zunyi, Southwest China. Ann Palliat Med 2020;9(5):3152-3161. doi: 10.21037/apm-20-1368 